XVII Simpósio Brasileiro

de Geografia Fisica Aplicada

I Congresso Nacional

de Geografia Física
OS DESAFIOS DA GEOGRAFIA FÍSICA NA FRONTEIRA DO CONHECIMENTO

Instituto de Geociências - Unicamp

Campinas - SP

28 de Junho à 02 de Julho de 2017

\title{
PAISAGENS DO MUNICÍPIO DE MARABÁ A PARTIR DE UMA VISÃO GEOSSISTÊMICA
}

\author{
Maria Rita Vidal ${ }^{\text {(a) }}$, Abraão Levi dos Santos Mascarenhas (b) \\ (a) Faculdade de Geografia,Universidade do Sul e Sudeste do Pará- Unifesspa,ritavidal @ unifesspa.edu.br \\ (b) Faculdade de Geografia,Universidade do Sul e Sudeste do Pará- Unifesspa, abraaolevi@ unifesspa.edu.br
}

\section{EIXO: SOLOS E PAISAGENS}

\begin{abstract}
Resumo
A cidade de Marabá objeto de estudo desta pesquisa, localiza-se na meso-região Sudeste do Pará, caracteriza-se pela ocorrência de paisagens diversificadas sob o domínio das planícies fluviais Apresentam ainda um elevado uso do solo urbano que estabelece áreas sujeitas a riscos relacionados a inundações. Assim, o objetivo deste trabalho é identificar e classificar as paisagens da cidade de Marabá, cartografando as diferentes tipologias como meio para subsídio ao planejamento ambiental e o uso sustentável das paisagens. Para tanto, utilizou-se dos pressupostos da geoecologia das paisagens com base na análise sistêmica. É apresentada uma proposta de tipologias de paisagens para o perímetro urbano de Marabá em função de suas diferenciações de altitudes e tipos vegetacionais, indicando um quadro de Unidades de Paisagens no mapa. Finalmente apresenta-se um mapa com as unidades de paisagens do perímetro urbano do município de Marabá.
\end{abstract}

Palavras chaves: Geoecologia, classificação das paisagens, sistemas geoinformativo.

\section{Introdução}

As cidades amazônicas estão ligadas aquilo que lhe é naturalmente específicos, as "amazonidades" (abundância das águas, igarapés, florestas de terra firmas e inundadas, as chuvas convectivas, óleos naturais, o açaí, o ribeirinho, a cerâmica, as canoas, e a biodiversidade efervescente), as amazonidades são assim, detentoras de uma dinâmica natural intensa em função dos recursos naturais que as permeiam.

A implementação dos grandes projetos de desenvolvimento e as relações de uso e ocupação do solo, estabelecidas nas cidades Amazônicas, estão levando os sistemas ambientais a um estado crítico de manutenção das relações de interconexão de fluxos de matéria e energia, que fundamenta as reações evolutivas dos geossistemas como um todo. Os estudos de Coelho et al. (2006) demonstraram que, somente, no período de 1984-2001 os castanhais foram substituídos pelas atividades pecuárias, sendo produto/causa das políticas de desenvolvimento implementadas na região, essas alterações nos sistemas ambientais refletem problemas nos mecanismos de auto-regulação e auto-organização. Essas alterações provocadas pelo ser humano e/ou pela natureza levam a modificações das funções ambientais como: produção, regulação, transporte e acumulação de matérias e energias. Importa saber que as paisagens e seus componentes sempre sofreram transformações nos seus aspectos estruturais e fisionômicos, resultantes de processos físicos e biológico, porém, aliados a isso, ocorre a intensificação dos processos de alterações pelas ações antrópicas. Dessa forma, é necessário analisar a 
paisagem em seu conjunto, compreendendo a sua constituição por vários elementos, físicos, biológicos e antrópicos, e que estes, estão relacionados de tal forma que qualquer modificação em um elemento leva a modificações e/ou alterações na paisagem como um todo.

Essa análise baseia-se nos estudos dos tipos de paisagens/unidades geoecológicas, suas interações e relações, em uma visão de totalidade dinâmica (RODRIGUEZ; SILVA, 2002). Assim, percebe-se a necessidade de desenvolver pesquisas que fortaleçam estudos sobre a classificação das paisagens e seu funcionamento, imprescindível a um planejamento ambiental que considere as potencialidades e os limites físicos. Na prática, o conhecimento sobre a tipologia, estrutura e funcionamento das paisagens contribui para o desenvolvimento de atividades de uso e ocupação mais racionais. Verifica-se, assim, a necessidade de dispor de estudos de casos concretos que permitam enriquecer a relação entre a análise geoecológica e sua aplicabilidade nos estudos das paisagens, subsidiando o planejamento e o ordenamento ambiental.

Pelo exposto, o objetivo do trabalho se pauta na classificação das paisagens do perímetro urbano do município de Marabá, apresentando suas tipologias cartograficamente como meio para o planejamento ambiental e o uso sustentável das paisagens.

Nesse contexto, a classificação das paisagens se faz de extrema importância na caracterização dos aspectos ambientais e sócio culturais. No caso específico do Município de Marabá, os fundamentos de uma classificação das paisagens, equivale ao estudo básico para determinar o estado e situação ambiental sob todos os espaços inclusos na região.

Procedimento esse que, em face dos aspectos físico-regionais próprios do Sudeste Paraense exige critérios de classificação tipológica, fato que por sua vez induz a busca por elaboração de cenários e modelos de auto-regulação adaptável as especificidades de cada sub-unidade classificada.

\section{Metodologia}

\subsection{Caracterização da área de estudo}

A cidade de Marabá, situa-se na meso-região Sudeste do Pará, com uma distância de aproximadamente $478 \mathrm{Km}$ da capital-Belém. O município de Marabá, limita-se com os seguintes municípios, ao norte, os municípios de Itupiranga, Nova Ipixuna e Rondon do Pará; ao sul, os municípios de Parauapebas, Eldorado dos Carajás e São Geraldo do Araguaia; a leste, os municípios de São Domingos do Araguaia, São João do Araguaia e Bom Jesus do Tocantins; a oeste, o município de Novo Repartimento, Figura 1. 


$\begin{aligned} & \text { XVII Simpósio Brasileiro } \\ & \text { de Geografia Fisica Aplicada }\end{aligned}$
$\begin{aligned} & \text { I Congresso Nacional } \\ & \text { de Geografia Física }\end{aligned}$

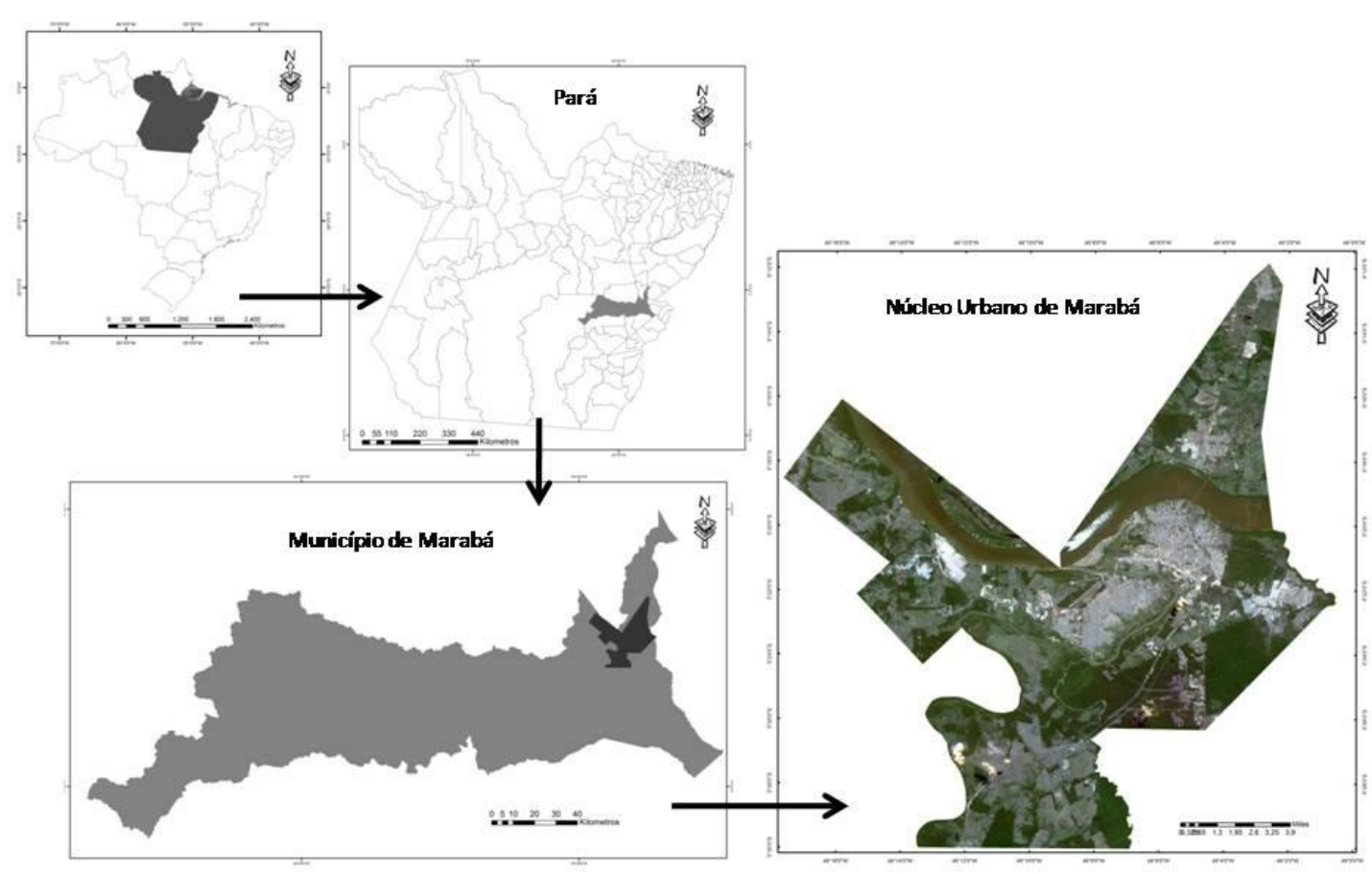

Figura 1- Localização geográfica do Núcleo Urbano de Marabá.

Fonte: IBGE (2017), Organização: Maria Rita Vidal.

A cidade de Marabá está situada em uma área de planície fluvial em um contexto de baixas altitudes (Depressão interplanáltica do Araguaia-tocantins), sofrendo com as enchentes em decorrência da morfotopografia e da influência direta de dois rios: o Itacaiúnas e o Tocantins.

A área em estudo corresponde assim, a um sistema complexo, onde podem ser encontrados ambientes alterados pela ação antrópica, como os serviços de terraplanagem executado por técnicas de engenharias que visa a alocação de empreendimentos imobiliários em terrenos colinosos ou em espaços que deveriam ser áreas de proteção permanente (APP), ocupadas por residências de baixo padrões que tornam esse ambiente vulnerável à processos de inundações e alagamentos. Os rios Tocantins e Itacaiúnas delimitam os setores urbanos da cidade de Marabá, sendo dividida em núcleos urbanos distintos (Marabá Pioneira, Cidade Nova, Nova Marabá, São Felix e Morada Nova). A confluência desses rios configura-se como uma célula sistêmica com dinâmica e funcionamento que levam consequências diretas da ordem inundações e alagamentos ao núcleo urbano da cidade de Marabá, sobretudo nos setores/bairros com menor topografia como Marabá Pioneira, Santa Rita, Santa Rosa, Cidade Nova, e as folhas 33 e 14 no Núcleo Nova Marabá1.

\footnotetext{
${ }^{1}$ A cidade de Marabá não tem definido em seu Plano diretor o que seriam bairros, núcleos urbanos, assim é que em alguns momento na presente redação pode aparecer núcleo urbano e em outro momento pode aparecer setor urbano.
} 
XVII Simpósio Brasileiro

de Geografia Fisica Aplicada

I Congresso Nacional

de Geografia Física
OS DESAFIOS DA GEOGRAFIA FÍSICA NA FRONTEIRA DO CONHECIMENTO

Instituto de Geociências - Unicamp

Campinas - SP

28 de Junho à 02 de Julho de 2017

\subsection{Pressupostos Teóricos na Análise Geoecológica:}

A Geoecologia das Paisagens tem seus antecedentes, na definição de Karl Troll por volta dos anos 30 do século XX, sendo considerada como a disciplina que analisava funcionalmente a paisagem. Tratava-se, pois, não de estudar apenas as propriedades dos geossistemas no estado natural, mas procurar as interações o com os sistemas sociais e culturais, em articular a paisagem natural e a paisagem cultural (RODRIGUEZ E SILVA, 2002).

O estudo das paisagens proposto por Sotchava (1977-1978) fundamenta-se nessa categoria como um sistema, no qual deve atender aos enfoques estruturais, funcionais e dinâmico-evolutivos. Para Sotchava (1977), cada categoria de geossistema situa-se em um ponto do espaço terrestre, sendo que este deve ser analisado como pertencente a um determinado lugar da esfera terrestre. Sotchava também fez divisões para estudar o geossistema considerando três ordens escalares de análise nos estudos dos geossistemas - planetário, regional e topológico, para cada ordem apresenta-se uma escala e uma dinâmica particular de análise.

Essa visão de paisagem permite sua consideração como unidade do meio natural, como um dos sistemas que entram em interação com os sistemas sociais, para formar o meio ambiente global, ou seja, os sistemas ambientais. Estudar a dinâmica e a organização espacial se constituem em um dos objetivos da ciência geográfica, que se utiliza de diferentes métodos e concepções variadas nas pesquisas referentes à análise do espaço geográfico.

Contudo, não basta apenas estudar e descrever os fatos geográficos, é preciso mostrar de que maneira eles se interligam, o que requer uma visão integrada do conhecimento dos processos e componentes que dinamizam e formam o espaço. Nesse contexto, a análise geoecológica permite apreender as organizações espaciais, esta surge a partir da década de 1970, com as discussões cada vez mais prementes sobre as questões ambientais.

A geoecologia descansa sobre a concepção dialética materialista da interação natureza-sociedade e representa uma base sólida para o conhecimento da evolução do potencial e da otimização dos recursos naturais e do ordenamento do território, com manejos mais adequados para cada unidade territorial delimitada (VIDAL, 2014). Nos anos 1960 do século XX, Victor Sotchava, elaborou a Teoria dos Geossistemas, utilizando toda a teoria sobre paisagens (Landschaft) elaborada pela Escola Russa. Ele interpretou essa herança sob uma visão da Teoria Geral de Sistemas. Isso significava que o conceito de Landschaft (paisagem natural) foi considerado como sinônimo da noção de geossistema (RODRIGUEZ E SILVA, 2002).

Uma das vantagens da aplicação do método sistêmico é seu caráter de flexibilidade, uma vez que possibilita a utilização através do método indutivo ou dedutivo. Por outro lado, a perspectiva quantitativa oferece amplas possibilidades de tratamento dos dados desenvolvidos por computadores por elaborações de cenários e modelos como bem abordados por Christofoletti $(1979 ; 1989)$. As Unidades geoecológicas se individualizam pelo clima, relevo, clima, solos, vegetação, ou mesmo pelo 
XVII Simpósio Brasileiro

de Geografia Fisica Aplicada

I Congresso Nacional

de Geografia Física
OS DESAFIOS DA GEOGRAFIA FÍSICA NA FRONTEIRA DO CONHECIMENTO

Instituto de Geociências - Unicamp

Campinas - SP

28 de Junho à 02 de Julho de 2017

arranjo estrutural da litologia (ROSS, 1992). Estas têm em sua delimitação aspectos complexos, pois a sua existência é condicionada pela dinâmica e interação de seus diversos componentes naturais. A categoria de análise das unidades geoecológicas é o geosssistema, este é definido como formação natural, antropo-natural, capaz de produzir recursos (ARMAND, 1984). Os métodos de análises paisagísticas na investigação geoecológica se define como a análise das paisagens na qual um conjunto de métodos e procedimentos analíticos permitem conhecer e explicar as regularidades estruturais e funcionais das paisagens (MONTEIRO, 2000).

\subsection{Métodos}

O trabalho segue as proposições apresentadas pela Metodologia adotada por (RODRIGUEZ, SILVA e CAVALCANTI, 2004), onde, a partir da integração dos componentes naturais e elementos dos sistemas antrópico, é possível identificar e representar cartograficamente as unidades geoecológicas que compõem o conjunto paisagístico de Marabá-pa, para tanto segue-se as seguintes etapas:

- Coletas de campo

Para a efetivação da identificação e delimitação das unidades foram realizados levantamentos de campo, onde parte das informações sobre as condições físicas e geográficas da área urbana foram conferidas e organizadas, a partir da realização dos trabalhos de campo (aplicação de fichas de campos), seguindo a metodologia sistêmica.

Em campo, foram realizadas observações diretas da estrutura e dinâmica de cada uma das unidades identificadas, juntamente com o levantamento específico das principais formas de uso e ocupação e os impactos ambientais com seus possíveis efeitos.

- Tabulação de dados

Os resultados dos dados serviram para a elaboração da classificação e delimitação das unidades geoecológicas. Como produto da coleta e análise de campo, além da elaboração dos mapas, foram produzidos matrizes de causas e efeitos, quadros-sínteses e perfis com os resultados da pesquisa, indicando as potencialidades, limitações e problemas da reserva. Além disso, foram interpretadas imagens orbitais que abrangem o Município para a constituição de figuras ilustrativas, a fim de alcançar uma melhor compreensão das questões aqui apresentadas.

- Aplicação de técnicas cartográficas

A aplicação de técnicas de cartografia é de relevância extrema para a compreensão da base física. Considerando que a área em estudo localiza-se em uma região de intensa dinâmica natural, que está em constante mudança (dinâmica), a atualização dos registros de uso do solo e da dinâmica da área faz da cartografia uma técnica imprescindível para a compreensão do trabalho. Os caminhos que se apresentam neste tópico foram traçados a partir da obtenção de um mapa básico e da interpretação da 
cena (SRTM V4). As imagens orbitais foram interpretadas visualmente, e em seguida elaborado o "over lay" (camadas ou shapefiles), para ser efetuada a checagem de campo.

A partir da reambulação, foram locadas as unidades de paisagens (feições) identificadas em campo, com a finalidade de confeccionar o mapa de unidades de paisagens, com suas formas de uso e ocupação, e os mapas de impactos ambos na escala de 1:75.000.

\section{Resultados e Discussão}

A aplicação de metodologia para a identificação, delimitação e classificação das unidades geoecológicas de marabá, possibilitaram chegar a cinco unidades geoecológicas representativas para a área urbana de Marabá, (Figura 2), sendo estas divididas em Subunidades Geoecológicas.

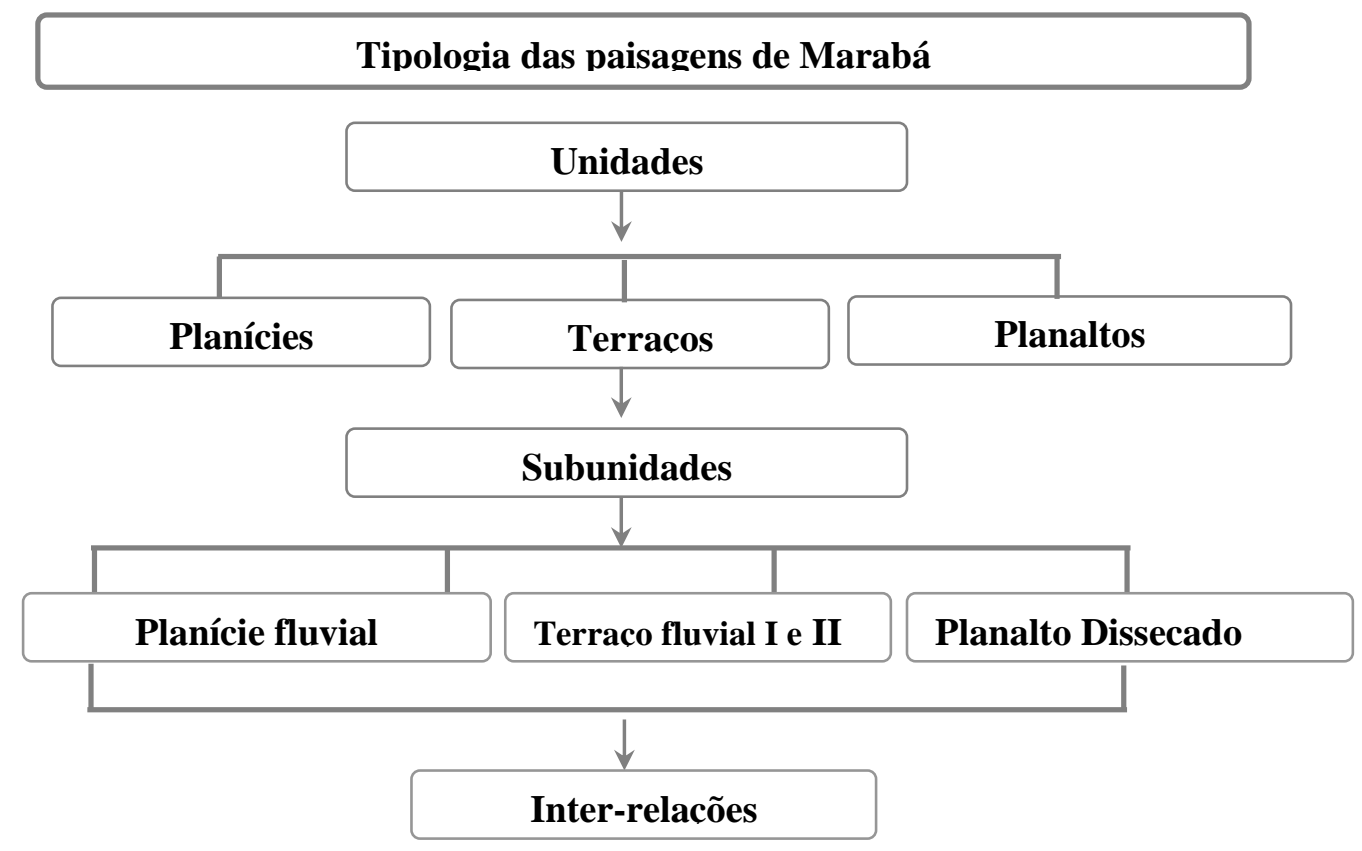

Figura 2 - Organograma das unidades de Paisagem do núcleo urbano de Marabá- PA.

Fonte: Elaboração dos autores.

\section{- Unidades geoecológicas de Marabá}

Como principal resultado, a pesquisa apresenta o mapa das unidades de paisagem do perímetro Urbano de Marabá (um esboço preliminar), uma vez que é preciso ainda detalhar as subunidades existentes. A delimitação de unidades de Paisagem se mostra pela complexidade de entender a interação entre atributos físicos naturas e antrópicos, este interagem e conferem aspectos importantes como fragilidade, riscos, impactos, etc. Para a classificação das unidades de paisagem do perímetro urbano de Marabá, a topografia foi a base para a classificação inicial, uma vez que a vegetação no espaço urbano se mostra como inexpressiva para tal classificação. Assim, a definição dos 
XVII Simpósio Brasileiro

de Geografia Fisica Aplicada

I Congresso Nacional

de Geografia Física

\section{OS DESAFIOS DA GEOGRAFIA FÍSICA NA FRONTEIRA DO CONHECIMENTO \\ Instituto de Geociências - Unicamp Campinas - SP \\ 28 de Junho à 02 de Julho de 2017}

compartimentos geomorfológicos na delimitação das Unidades de paisagem se deu através dos apontamentos de Ross (1990).

O mapa de Unidade de paisagem foi elaborado e em segundo plano foram consideradas as formas de uso e ocupação, fundamentais para as analises antrópicas na paisagem em questão. Para a área em estudo têm-se o esboço preliminar das unidades de paisagem, delimitadas em 4 unidades homogêneas para a área de estudo. Ver figura 3.
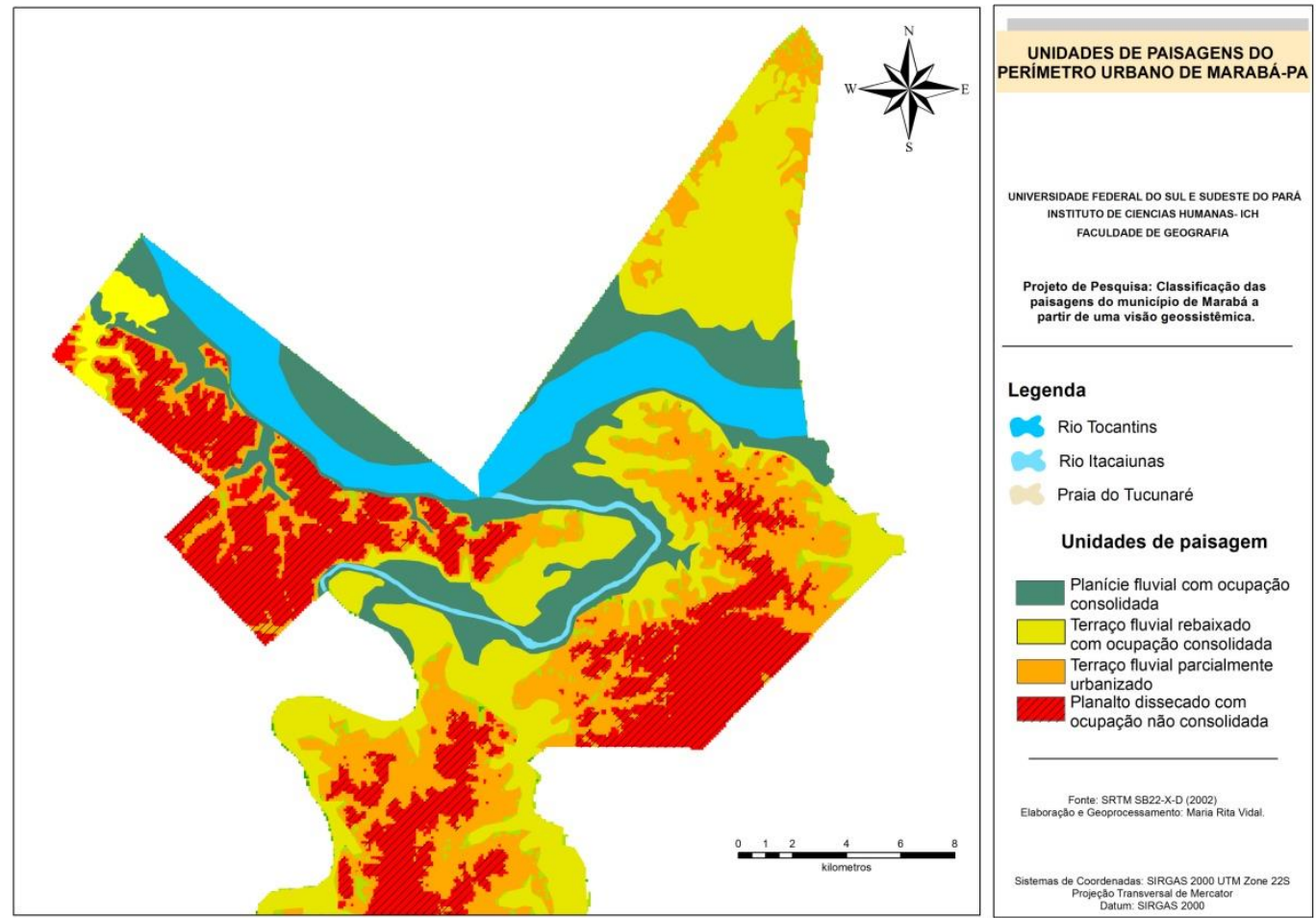

Figura 3- Mapa delimitando as Unidades de Paisagem do Perímetro Urbano de Marabá-PA, a partir do MDE. Fonte: Elaboração dos autores.

a) Planície fluvial com ocupação consolidada- com as menores cotas altimétricas margeiam os rios que cortam a cidade de Marabá, escoam canais de primeira ordem que detém ambiente com características úmidas. A planície fluvial corresponde ao sistema formado pela confluência dos Rios Itacaiúnas e Tocantins, a confluência desses rios configura-se como uma célula sistêmica com dinâmica e funcionamento que levam consequências diretas da ordem de enchentes, inundações e alagamentos na cidade de Marabá, sobretudo nos setores/bairros com menor topografia como o núcleo Marabá Pioneira, vilas Santa Rita e Santa Rosa, e ainda no núcleo Cidade Nova e Núcleo Nova Marabá. A planície em questão encontra-se totalmente ocupada pela mancha urbana, a planície fluvial sofre influência direta das formas de uso e ocupação, sobretudo pela impermeabilização ocasionada para a construção dos imóveis e dos arruamentos (ruas, calçamento). Observa-se aterro de algumas áreas para construções (moradias) o que vem ocasionando erosão hídrica, perca de nutrientes e fragmentação do habitat. A posição na paisagem dessa unidade de paisagem uma área de acumulação 
XVII Simpósio Brasileiro

de Geografia Fisica Aplicada

I Congresso Nacional

de Geografia Física
OS DESAFIOS DA GEOGRAFIA FÍSICA NA FRONTEIRA DO CONHECIMENTO

Instituto de Geociências - Unicamp

Campinas - SP

28 de Junho à 02 de Julho de 2017

de matéria e energia, pois recebe sedimentos/nutrientes/águas/ etc das áreas mais elevadas em seu entorno.

b) Terraço Fluvial rebaixado com ocupação consolidada- situada entre os compartimentos da Planície fluvial e do Planalto dissecado é formada por depósitos fluviais Holocenos, onde areias fluviais foram retrabalhadas na superfície. A ação dos processos pedogenéticos levam a constituição/formação de Neossolos Quartzarenicos e Argissolos, com predomínio de áreas planas e suavemente onduladas, com cotas altimétricas em torno de 80 metros, apresenta-se com degraus mais suaves nas proximidades da planície fluvial. O primeiro nível do terraço formado pelo Rio Tocantins e Itacaiúnas, sua cobertura vegetal encontra-se dispersa pelo núcleo urbano com presença de porte arbóreo em áreas preservadas como se verifica na Mata dentro da área do do exército brasileiro (área militar). A área apresenta ocupação consolidada, indicando variações quanto ao seu grau de ocupação. A intensa interferência das ações antrópicas nessa unidade há caracteriza como uma unidade instável.

c) Terraço Fluvial parcialmente urbanizado - Com amplitudes altimétricas variando de 80 á 100 metros, se apresenta com relevos ondulados á suave ondulado, cortada pela rede de drenagem do riacho "Grota Criminosa" que pelos aspectos da urbanização confere média energia e velocidade de escoamento as águas, verificando-se a ocorrência de áreas susceptíveis a erosão e alagamentos. Os solos guardam sua gênese na formação de latossolos e argissolos também susceptíveis à erosão. Apresentando urbanização parcial, guarda local para os grandes equipamentos urbanos de Marabá como o aeroporto da cidade. Essa unidade pode ser definida como instável, pela ocupação desordenada na área.

d) Planaltos dissecados com ocupação não consolidada - caracteriza-se por apresentar planaltos dissecados com encostas em patamares com altitudes acima de $169 \mathrm{~m}$, recobertos por vegetação de Floresta Ombrófila aberta, intercalados por áreas para fins de agropecuária, e ainda é possível verificar a ocorrência de açaí (Euterpe oleracea) disperso na paisagem, ambos assentados sob Neossolos, Latossolos e Argissolos, com a presença de canais temporários. Embora o relevo seja mais acidentado, nessa unidade de paisagem pode-se aferir um ambiente estável, talvez esse fator aconteça em função da ocupação não está ainda consolidada. Essa unidade é caracterizada por ser uma área produtora, em que garante o fluxo de matéria e energia para o restante das áreas mais rebaixadas, tendo grande influência no controle da formação e evolução da paisagem como um todo.

\section{Considerações finais}

As unidades delimitadas expressam certa complexidade das paisagens que compõem o perímetro urbano de Marabá. O sítio urbano de Marabá assenta-se predominantemente sob a planície fluvial e os terraços, o processo de ocupação desordenada nessas unidades de paisagem

Está gerando a insustentabilidade dessas unidades, com comprometimento dos fluxos de matéria e energia que dinamizam os sistemas ambientais. Dessa forma, torna-se imperativo o constate 
OS DESAFIOS DA GEOGRAFIA FÍSICA NA FRONTEIRA DO CONHECIMENTO

Instituto de Geociências - Unicamp Campinas - SP

28 de Junho à 02 de Julho de 2017

acompanhamento das unidades de paisagens, para direcionar novos estudos, na prática, o conhecimento sobre a tipologia, estrutura e funcionamento das paisagens contribui para o desenvolvimento de atividades de uso e ocupação mais racionais minimizando os impactos ambientais.

As questões associadas ao estado das unidades geoambientais tiveram suas síntese retratada em cada unidade, sendo necessários novos estudos para aprofundar suas características de estabilidade e instabilidade. Em geral o critério de estado geoecológico de cada unidade possibilitou sua caracterização geral, já que processos de erosão laminar, desmatamento de áreas de preservação permanente, entalhamento por ações antrópicas em relevos colinosos configuram estados geoecológicos as unidades em tela.

A teoria da geoecologia das paisagens foi essencial a aplicação de áreas urbanas, por apresentar a possibilidade de caracterizar os estados, dinâmicas e funcionamentos das unidades geoecológicas associadas as ações antropogênicas. Sendo possível associar a metodologia as questões do planejamento urbano. Qualificar o planejamento urbano com a teoria geoecológica é perspectiva sine qua non do desenvolvimento urbano.

\section{Bibliografia}

ARMAND, A.D. Los processos del auto desarrollo y ladirección en los geosistemas. In: Conceptos principales, modelos y métodos de las investigações geográficas generales. Rússia: Instituto de Geografia de la Academia de Ciências de la URSS. 1984. p. 88-96.

COELHO. M. C.N; MONTEIRO. M. A.; FERREIRA. B. C.; BUNKER. S. Impactos ambientais da estrada de ferro Carajás no Sudeste do Pará. Parte IV. In: TEXEIRA. B. G. (Org.) Carajás: geologia e ocupação humana. Belém, Museu Paraense Emilio Goeldi, 2006.

CHRISTOFOLETTI, A. Análise de sistemas em Geografia. São Paulo: Hucitec, 1979.

CHRISTOFOLETTI, A. Modelagem de sistemas ambientais. São Paulo: Edgar Blücher, 1998.

MONTEIRO. C. A. F. Geossistema: a história de uma procura. São Paulo, Contexto, 2000

RODRIGUEZ, J. M. M. Análise e síntese de abordagem geográfica de pesquisa para o planejamento ambiental. Revista do Departamento de Geografia de FFLCH/USP. São Paulo: v.9. 1994.

RODRIGUEZ, J. M. M.; SILVA, Edson Vicente da. CAVALCANTI, Agostinho Paula Brito. Geoecologia das paisagens: uma visão geossistêmica da análise ambiental. Fortaleza: Editora UFC, 2004.

RODRIGUEZ, J. M. M;.SILVA, Edson Vicente da. A classificação das paisagens a partir de uma visão geossistêmica. Mercator. ano 1, n.1, 2002.

ROSS, J. L. S. O registro cartográfico dos fatos geomórficos e a questão da taxionomia do relevo. Revista do Departamento de Geografia da USP. São Paulo: n. 6. 1992. 17-29p.

SILVA, Edson Vicente da. Geoecologia da paisagem do litoral cearense: uma abordagem a nível de escala regional e tipológica. 1998. Tese de Professor Titular, Departamento de Geografia, Universidade Federal do Ceará, Fortaleza, 1998.

SOTCHAVA, V.B. O estudo de geossistemas. Método em questão, 16. São Paulo: IG-USP. 1977.

VIDAL, M. R. Geoecologia das Paisagens: fundamentos e aplicabilidades para o planejamento ambiental no baixo curso do rio Curu-Ceará-Brasil. 2014. 190f. Tese (Doutorado em Geografia) - Universidade Federal do Ceará. Fortaleza, 2014. 